\title{
AVALIAÇÃO DE DIFERENTES PRÉ-TRATAMENTOS QUÍMICOS EM BIOMASSAS DE BARU PARA OBTENÇÃO DE BIOPRODUTOS
}

Evaluation os different chemical pre-treatments in baru biomass to obtain bioproducts

Evaluación de diferentes pretratamientos químicos en biomasa barú para obtener bioproductos.

\section{Cláudio Carneiro Santana Junior ${ }^{1}$, Polyana Morais de Melo², Joelma Katharine Souza} Romano $^{3}$, Michele Cristiane Diel Rambo ${ }^{4}$, Magale Karine Diel Rambo*1,2

${ }^{1}$ Programa de Pós-Graduação em Ciências Ambientais, Universidade Federal do Tocantins-UFT, Palmas, Brasil.

${ }^{2}$ Programa de Pós-Graduação em Ciências e Tecnologia de Alimentos, Universidade Federal do Tocantins-UFT, Palmas, Brasil

${ }^{3}$ Graduação em Engenharia Ambiente, Universidade Federal do Tocantins-UFT, Palmas, Brasil.

${ }^{4}$ Instituto Federal do Tocantins-IFTO, Palmas, Brasil.

*Correspondência: Laboratório de Ciências do Ambiente, Universidade Federal do Tocantins, Av. NS 15, 109 Norte, Palmas, Tocantins, Brasil.CEP:77.010-090.e-mailmagalerambo@uft.edu.br.

\section{RESUMO}

O baru (Dipteryx alata Vog.) possui grande potencial energético para a produção de bioprodutos, a partir do residual do fruto. $\mathrm{O}$ objetivo do trabalho foi caracterizar a biomassa residual (mesocarpo e endocarpo) de baru para a obtenção de bioprodutos em processos de biorrefinarias. Cada amostra foi analisada em duplicata e o espectro médio foi utilizado. Foram realizadas análises aproximadas de umidade, cinzas, VMC, FC e matéria orgânica. As biomassas foram pré-tratadas com peroxidativos e solução alcalina submetidos à hidrólise ácida para produção de açúcares. As caracterizações físico-químicas mostraram que, em geral, as biomassas do mesocarpo e endocarpo de baru podem fornecer uma gama de produtos de valor agregado, pois seus parâmetros se encaixam nas exigências da biorrefinaria, tais como: alto teor de carboidratos, baixo teor de umidade, extrativos e cinzas. Maiores teores de lignina contribuem para a obtenção de insumos aromáticos e carvão, do qual foram obtidos para o mesocarpo bruto.

Palavras-chave: Produção de açúcar; rendimento de lignina; bioprodutos.

\section{ABSTRACT}

Baru (Dipteryx alata Vog.) has great energy potential for the production of bioproducts from the residual of the fruit. The objective of this work was to characterize baru residual biomass (mesocarp and endocarp) to obtain bioproducts in biorefineries processes. Each sample was analyzed in duplicate and the average spectrum was used. Approximate analyzes of humidity, ash, VMC, FC and organic matter were performed. The biomasses were pretreated with peroxidatives and alkaline solution submitted to acid hydrolysis for sugar production. The physicochemical characterization showed that, in general, the endocarp and mesocarp biomass of baru can provide a range of value added products, as their parameters fit the biorefinery requirements, such as: high carbohydrate content, low carbon content. moisture, extractives and ashes. Higher lignin contents contribute to the obtaining of aromatic inputs and coal, which were obtained for the raw mesocarp.

Keywords: Sugar production; Lignin yield; Bioproducts. 


\section{RESUMEN}

Baru (Dipteryx alata Vog.) Tiene un gran potencial energético para la producción de bioproductos del residuo de la fruta. El objetivo de este trabajo fue caracterizar la biomasa residual de barú (mesocarpio y endocarpio) para obtener bioproductos en procesos de biorrefinerías. Cada muestra se analizó por duplicado y se utilizó el espectro promedio. Se realizaron análisis aproximados de humedad, ceniza, VMC, FC y materia orgánica. Las biomasas se trataron previamente con peroxidativos y solución alcalina sometida a hidrólisis ácida para la producción de azúcar. La caracterización fisicoquímica mostró que, en general, la biomasa de endocarpio y mesocarpio de baru puede proporcionar una gama de productos de valor agregado, ya que sus parámetros se ajustan a los requisitos de la biorrefinería, tales como: alto contenido de carbohidratos y bajo contenido de carbono. Humedad, extractivos y cenizas. Los contenidos más altos de lignina contribuyen a la obtención de insumos aromáticos y carbón, que se obtuvieron para el mesocarpio crudo.

Descriptores: Producción de azúcar; rendimiento de lignina; bioproductos.

\section{INTRODUÇÃO}

A preservação do meio ambiente é um assunto presente em diversas pautas de discussão governamental e dentro das indústrias. A química está presente em todos os processos, e na maioria das vezes, foi intitulada ameaçadora devido a formação de subprodutos tóxicos e a contaminação do ambiente e do próprio homem (Sheldon e Woodley, 2017).

A formação de compostos por meio da chamada química verde, vem alcançando espaço no setor industrial, visto que esta propicia novos processos cada vez menos prejudiciais ao meio ambiente (Sheldon, 2016; Rothenberg, 2017).

O uso da biomassa disponível no cerrado, é uma alternativa para produção de compostos com valores agregados, que podem ser utilizados em diversos ramos industriais. Para que estes compostos sejam produzidos, a junção de técnicas químicas e biotecnológicas se faz necessária para que a biomassa seja totalmente aproveitada, e os impactos ambientais sejam mitigados (Lancefield, et al., 2017; Blamey et al., 2017).

O Baru, (Dipteryx alata Vog.), é um fruto nativo do cerrado brasileiro, pertencente à família Faboideae. A árvore do baru, chega a medir 25m, sendo muito encontrada em solos mais férteis. $\mathrm{O}$ baru é muito utilizado devido suas diversas aplicações, como uso alimentar, madeireiro, medicinal, industrial, paisagístico e na recuperação de áreas degradadas (Lemos et al., 2012).

O fruto é do tipo drupa, ovoide e apresenta uma aparência marrom-clara, contendo apenas uma semente comestível. Em virtude de suas características químicas, existe interesse tecnológico em suas frações, formadas pelo epicarpo, mesocarpo e endocarpo do baru, composta principalmente por amido, lignina, açúcares, vitaminas e óleos essenciais (Fernandes et al., 2010; Takemoto e Okada, 2001; Lemos et al., 2012; Bento et al., 2014).

Os materiais lignocelulósicos, são os principais constituintes de diversas biomassas, e possui mecanismos de resistências que impedem a ação de microrganismos e animais para degradação dos açúcares presentes no material. Cada prétratamento tem seu próprio efeito sobre a celulose, hemicelulose e lignina; os três principais componentes da biomassa lignocelulósica. Desta forma, a primeira etapa de utilização e caracterização da biomassa em biorrefinarias deve ser o pré-tratamento que tem a função de solubilizar seus constituintes em açúcares redutores (Hendriks e Zeeman, 2009; Pacheco, 2011).

Há um grande interesse científico no uso do baru, devido sua composição química e utilização como biomassa renovável. Desta forma, o objetivo 
deste trabalho foi caracterizar o fruto do baru, mesocarpo e endocarpo, de acordo com seu potencial energético para o uso da sua biomassa na geração de novos produtos e identificar a partir de pré- tratamentos o teor de açúcares redutores, redução do teor de extrativos e remoção eficientemente a lignina.

\section{MATERIAIS E MÉTODOS}

\section{Matéria prima}

Os frutos de Baru (Dipteryx alata Vog.) utilizados foram coletados em Porangatu-GO, Brasil, em outubro de 2017, onde foram armazenados em embalagem de sacos plásticos. As amêndoas do baru foram retiradas manualmente com um auxílio de uma faca. Os frutos foram secos em estufa com circulação de ar (SolidSteel SSD 110L) a $105{ }^{\circ} \mathrm{C}$ por $12 \mathrm{~h}$, e separados manualmente o mesocarpo e o endocarpo lenhoso. Após as separações, ambas as amostras foram trituradas em moinho (moinho de tipo willye, modelo star FT 50, marca Fortenox), em sequência foram peneiradas até o tamanho de partículas de 48 mesh e armazenadas em frascos de vidros herméticos.

\section{Análise aproximada}

Os teores de umidade, cinzas e matéria volátil foram determinados de acordo com as normas ASTM (Sociedade Americana para Ensaios e Materiais, 2004), ASTM D 3173-87, ASTM D 3174-04 e ASTM D 3175-07, respectivamente. Os teores de carbono fixo (FC) e matéria orgânica (OM) foram obtidos de forma indireta, pela diferença do teor de cinzas mais o teor de matéria volátil para FC e pela diferença do teor de cinzas para OM. A extração foi realizado em um extrator Soxhlet, de acordo com NREL (2011a).

\section{Pré-tratamentos}

Os pré-tratamentos consistiram no uso de $\mathrm{H}_{2} \mathrm{O}_{2}(3 \%)$, em uma proporção de 1:20 (m/v) e no uso de $\mathrm{NaOH} 4 \%(\mathrm{~m} / \mathrm{v})$, em uma proporção de 1:40 $(\mathrm{m} / \mathrm{v})$. Ambos os pré-tratamentos permaneceram em agitação durante 3 horas a uma temperatura de 70 ${ }^{\circ} \mathrm{C}$.

A biomassa de mesocarpo foi submetida também a um processo de lavagem com água quente

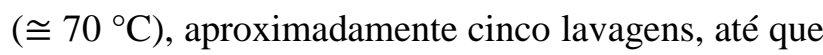
se observasse o liquido incolor no recipiente. Após o aquecimento, as biomassas foram lavadas com água destilada até $\mathrm{pH}$ neutro, filtrada sob vácuo, secas em estufa $\left(105^{\circ} \mathrm{C}\right)$ até atingir massa constante e mantida em dessecador. $\mathrm{O}$ rendimento foi calculado de acordo com Weerachanchai et al. (2014).

\section{Hidrólise ácida}

As amostras brutas e pré-tratadas $(300 \mathrm{mg}$ ) foram submetidas a uma hidrólise ácida de dois estágios, como descrito por NREL (2011b). No primeiro estágio, a amostra e o ácido sulfúrico a $72 \%$ (3 $\mathrm{mL}$ ) foram submetidos em banho maria a $30^{\circ} \mathrm{C}$ por $1 \mathrm{~h}$ e agitado a cada $10 \mathrm{~min}$. Na segunda etapa, $84 \mathrm{~mL}$ de água foram adicionados e as amostras foram autoclavadas (autoclave vertical, Phoenix) por $1 \mathrm{~h} \mathrm{a} 120^{\circ} \mathrm{C}$. Posteriormente foram filtradas a vácuo (LT 65, Limatec, acoplado) e armazenadas, separando a parte líquida para análises de açúcares e lignina solúvel e o sólido para obtenção do teor de lignina insolúvel em ácido, também conhecido como lignina de Klason.

\section{Quantificação do teor de lignina}

A lignina de Klason (KL) e a lignina solúvel em ácido (ASL) foram determinadas de acordo com Laboratório Nacional de Energia Renovável (NREL, 2011b). A ASL foi determinada em espectrofotômetro UV-Vis (HACH/Germany, DR5000) com comprimento de onda de $294 \mathrm{~nm}$ com 
de $\mathrm{H}_{2} \mathrm{SO}_{4}$ a $4 \%$ (m/v) solução do branco. O total de lignina (TL) é a soma da KL+ ASL. O teor de lignina deixado na biomassa pré-tratada (\%) foi definido como a massa de lignina deixada na biomassa pré-tratada/massa de lignina deixada na biomassa bruta.

\section{Quantificação de teor de açúcares totais}

A mistura da solução hidrolisada em ensaio com DNS (150 $\mu \mathrm{l}$ em $2850 \mu \mathrm{l})$, utilizou-se $1 \mathrm{~mL}$ do reagente DNS para cada $1 \mathrm{~mL}$ do hidrolisado, foi fervida durante 5 min e depois arrefecida em banho de água gelada e completado o volume $(10 \mathrm{~mL})$ com $8 \mathrm{~mL}$ de água destilada. A absorbância foi medida a $540 \mathrm{~nm}$ por um espectrofotômetro UV-vis (HACH/ Germany, DR5000) para quantificar o teor de açúcar. As concentrações de açúcares redutores totais foram calculadas a partir da curva padrão de D-glicose. A conversão de açúcar (\%) foi determinada como a massa de açúcares redutores totais pela massa de biomassa regenerada (Weerachanchai et al., 2014).

\section{Espectros visíveis próximos ao infravermelho}

Os espectros na região do infravermelho próximo foram obtidos em um espectrômetro Agilent Technologies (CARY 630 FTIR) de feixe único, no modo de reflectância difusa, na faixa de 650 a 4000nm (variação total) com incrementos de $0,5 \mathrm{~nm}$ e foram calculados a média de 32 varreduras. Os espectros de infravermelho por reflectância difusa serão transformados para absorbância (A) usando $A=\log 10(1 / R)$. Cada amostra foi analisada em duplicata e o espectro médio foi utilizado.

\section{Análises dos dados}

As análises estatísticas utilizaram o programa Origin 8.0 (Originlab) para construção dos gráficos e figuras ilustrativas (StatSoft, Estados Unidos, 2005).

\section{RESULTADOS E DISCUSSÃO}

\section{Rendimento de biomassa após os pré-tratamentos}

A figura 1 mostra que os pré-tratamentos na biomassa do mesocarpo de baru não obtiveram boas recuperações, nos pré-tratamentos tanto com $\mathrm{H}_{2} \mathrm{O}_{2}$ quanto o $\mathrm{NaOH}$ tiveram rendimentos baixos de recuperação de biomassa $(<20,0 \%)$. A hidrólise foi realizada apenas para biomassas pré-tratadas com água quente, do qual apresentou ser um tratamento menos agressivo, com um rendimento de recuperação, $30,32 \%$.

A perda de massa observada após esses pré-tratamentos pode ser atribuída à despolimerização de carboidratos/ hemi-celuloses e à solubilização de extrativos (Brienzo et al., 2014). Santos-Rocha et al. (2017) ao realizarem o pré tratamento com água quente em palha e sabugo de milho, obtiveram seus rendimentos mássicos finais de $47,7 \%$ e $42,0 \%$ respectivamente. Oliveira et al., (2014) descreveram que os rendimentos médios para estes tratamentos são de $47 \%$ a $55 \%$. Isso demonstra que este pré-tratamento ao ser realizado com a biomassa do mesocarpo do baru possui um rendimento de biomassa pouco abaixo dos padrões da literatura.

Figura 1. Comparativo dos rendimentos dos prétratamentos na biomassa do mesocarpo e endocarpo de Baru. 


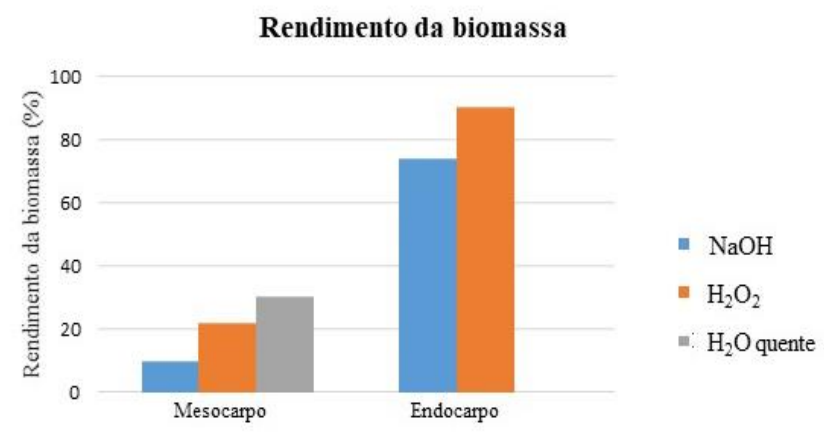

Em relação ao endocarpo do baru, o prétratamento com peróxido de hidrogênio $\left(\mathrm{H}_{2} \mathrm{O}_{2}\right)$, se mostrou mais eficiente e com menor perda de biomassa, que o tratamento alcalino com hidróxido de sódio $(\mathrm{NaOH})$, sendo a recuperação da biomassa de $90,72 \%$ e $74,24 \%$, respectivamente.

$\mathrm{O}$ peróxido de hidrogênio $\left(\mathrm{H}_{2} \mathrm{O}_{2}\right)$ é amplamente utilizado para solubilização da lignina em polpas de madeira altamente lignificadas para a produção de papel, do qual tem se mostrado eficientes em outras biomassas, como no bagaço da cana, capins residuais, fibras da casca de coco verde (Rabelo, 2007; Grasel, et al., 2017; Cabral, et al., 2017).

\section{Caracterização estrutural da biomassa}

Através da espectroscopia da região do VisNIR foi possível observar as estruturas da biomassa antes e após os pré-tratamentos. Na figura 2 apresentam bandas características na região de 840 $\mathrm{cm}^{-1}$, do qual são atribuídas a vibração $\mathrm{C}-\mathrm{H}$ fora do plano, provavelmente de estruturas de $\mathrm{R}_{2} \mathrm{C}=\mathrm{CHR}$ da molécula de lignina. Observa-se que nas amostras brutas (Figuras 2a e 2b) essa banda é mais proeminente em ambas as biomassas, enquanto que nos espectros de biomassas pré-tratadas, a intensidade é reduzida, o que significa que parte da lignina foi eficientemente removida após os prétratamentos.
Na região de $920 \mathrm{~cm}^{-1}$ também se observa o mesmo comportamento com bandas mais intensas e alargadas nas biomassas brutas (Figura 2b), atribuídas ao grupo $\mathrm{O}-\mathrm{H}$, devido à deformação angular fora do plano da ligação $\mathrm{C}=\mathrm{O}$ de ácidos carboxílicos, ou seja, parte desses ácidos foi removida após os pré-tratamentos, com espectros de aparência limpa, como é o caso principalmente, dos espectros submetidos a lavagem com peróxido de hidrogênio e hidróxido de sódio.

Figura 2. Espectros de infravermelho das biomassas brutas de mesocarpo (a) e endocarpo (b) de baru, e também depois de submetidos a diversos pré-tratamentos.

(a)

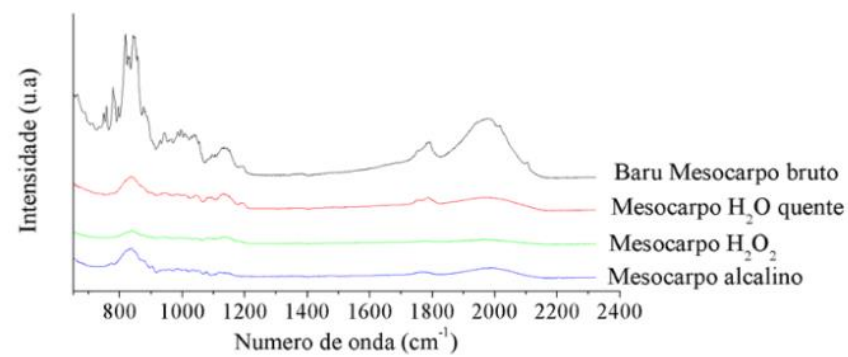

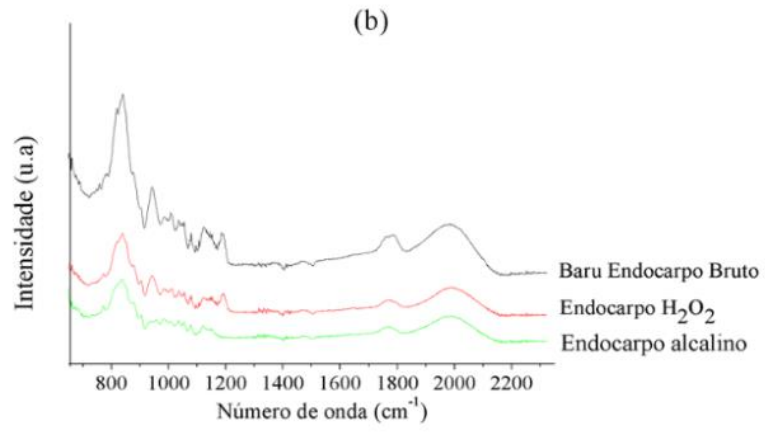

Em $1790 \mathrm{~cm}^{-1}$ temos uma banda característica de $\mathrm{C}=\mathrm{O}$ de anidridos, pouco visível após os pré-tratamentos (Figura 2a e 2b). No tratamento que incluiu apenas a lavagem da biomassa com água quente, na figura 2a para o mesocarpo percebe-se que os anidridos não foram totalmente removidos. Bandas para alenos terminais em $1950 \mathrm{~cm}^{-1}$ foram observadas atribuídas também a molécula de lignina e ambas as biomassas. 
Pela análise dos espectros, se observa que o pré-tratamento com peróxido foi o mais eficiente na remoção de lignina atribuída a duplas ligações.

O pré-tratamento com peróxido provoca ataques nucleofílicos que quebram a estrutura da lignina, solubilizando fragmentos de lignina ou hemiceluloses das ligações $\alpha$-O-4 (Fengel e Wegener, 1984). Esse pré-tratamento levou a um aumento no teor de açúcares e lignina, como resultado da remoção da hemicelulose (Figura 2b). Similarmente ao pré-tratamento com peróxido, o pré-tratamento alcalino contribui para a degradação da celulose, aumentando os níveis de açúcares. As condições de pré-tratamento alcalino possivelmente removeram a hemicelulose e a lignina em uma extensão com ligações de hidrogênio nas regiões amorfas das moléculas de celulose. Espera-se que este efeito aumente a fração de celulose cristalina, que tem maior recalcitrância em comparação com a fração amorfa. Em comparação, com o tratamento com peróxido, o tratamento alcalino reduziu o teor de lignina em cerca de $7 \%$.

$\mathrm{O}$ efeito de diferentes pré-tratamentos nos fatores importantes, que são o teor de lignina extraído, a produção de biomassa regenerada e o rendimento de açúcares redutores, foi investigado (Figura 3a e 3b). A conversão de açúcar e o teor de lignina extraída foram examinados para significar as propriedades melhoradas de biomassas pré-tratadas. As biomassas pré-tratadas, que possuem propriedades melhoradas para fornecer uma alta conversão de açúcar usada como fonte para produções de bioprodutos e possuem um baixo teor de lignina esquerda que reduz as resistências do processo de hidrólise, proporcionariam maior rendimento para a bioconversão.
No entanto, há ligeiros aumentos da conversão de açúcar (> 40\%) e uma diminuição da lignina extraída após o pré-tratamento com água quente. Isso proporciona eficiências extremamente altas neste pré-tratamento simples e rápido. Submetendo a amostra apenas a um processo de extração também se obteve bons resultados. Rendimentos de açúcares superiores a $25 \%$ e altas taxas de remoção de lignina ( $>20 \%$ ) foram obtidos.

\section{Composição química do baru}

Para verificar a influência na constituição química da biomassa, na Figura 3 tem-se a comparação das biomassas brutas, extraídas e prétratadas de acordo com seus respectivos teores de lignina ácida solúvel (ASL), lignina Klason (KL); resíduo ácido insolúvel (AIR); lignina total (TL). A determinação das características da biomassa, bem como o desenvolvimento de pré-tratamentos mais eficientes e econômicos para quebrar a recalcitrância da matriz lignocelulósica são importantes para o estudo do seu potencial energético, e assim seus principais produtos a serem obtidos (Seidl e Goulart, 2016).

As amostras de baru apresentaram uma ampla variação entre os pré-tratamentos. Na Figura 3a, o maior intervalo, em valores absolutos, foi observado para açúcares totais seguido do teor da lignina de Klason e lignina total.

Figura 3: Análise descritiva e estatística dos parâmetros da composição química do (a) mesocarpo do baru (b) endocarpo do baru, biomassa bruta, extraídas e diferentes pé-tratamentos (TS: açúcares totais; KL: lignina de Klason; ASL: lignina solúvel em ácido; TL: lignina total). 
(a)

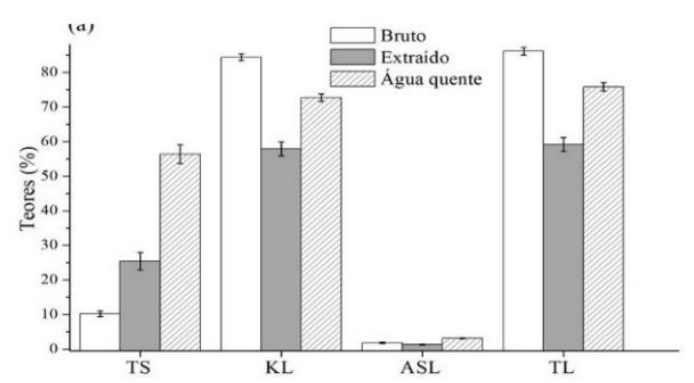

(b)



Quando observamos a figura $3 \mathrm{~b}$, os comportamentos dos intervalos mantem-se equilibrado para o teor de lignina de Klason e o teor de lignina total. Por outro lado, o menor intervalo para ambas (mesocarpo e endocarpo) foi para a lignina ácida solúvel. Esse resultado é favorável, quando o objetivo do trabalho é determinar as pentoses provenientes da hemicelulose. Dessa forma, mostra-se que os resultados encontrados para açúcares totais são representativos, não sendo contabilizado com a ASL. A hemicelulose tem sido amplamente utilizada na produção de bioprodutos devido ao fato de ser relativamente fácil de ser hidrolisada em seus monossacarídeos, liberando insumos de grande valor; eles também podem ser fermentados para fornecer outros produtos químicos importantes, como o etanol no caso de hexoses (Hayes, 2006).

De acordo com Rambo et al., (2015), as biomassas devem ter pelo menos $25 \%$ de carboidratos para se tornarem potenciais insumos para o fornecimento de bioprodutos. Pode-se notar que os açúcares totais para o endocarpo (figura 3b), não diferiram estatisticamente entre os tipos de tratamentos, com 5\% de significância, embora Seidl e Goulart (2016) relatam que cada pré-tratamento age de maneira diferente nas estruturas lignocelulósicas. Dessa forma, a quantidade de açúcares totais obtidas no endocarpo do baru não apresentou uma quantidade satisfatória. Já os obtidos para o mesocarpo (figura 3a), mostrou que o prétratamento com água quente obteve maior biodisponibilidade dos açúcares em relação a amostra bruta e extraída, apresentando ser menos agressivo a biomassa.

Outro parâmetro interessante notar, é a lignina de Klason, para o mesocarpo (figura 3 a) a amostra bruta apresentou melhores resultados. $\mathrm{Na}$ fig. 3b para o endocarpo, o tratamento oxidativo obteve melhor resultado para este parâmetro, seguido pela amostra bruta. Este resultado corrobora com Vale e Olsen (2013) ao utilizar o pericarpo bruto, ou seja, toda a parte considerada residual do baru (epicarpo, mesocarpo e endocarpo) para a produção de carvão, visto que esta produção é proveniente da lignina extraída da biomassa, concluiu que é um material de elevada dureza mostrando superior ao carvão de madeira.

\section{CONCLUSÃO}

Assim, constatou-se que o uso de recursos renováveis é importante para uma sociedade economicamente viável e ambientalmente correta. A biomassa residual caracterizada neste trabalho, mesocarpo e endocarpo de baru são abundantes e promissoras, o que as torna alternativas muito atrativas e que provavelmente se tornarão fatores de lucro e criação de empregos. As caracterizações físico-químicas mostraram que, em geral, todos os 
resíduos são potenciais candidatos e podem fornecer uma gama de produtos de valor agregado, pois seus parâmetros se encaixam nas exigências da biorrefinaria, tais como: alto teor de carboidratos, baixo teor de umidade, extrativos e cinzas. Maiores teores de lignina contribuem para a obtenção de insumos aromáticos e carvão, inclusive para uso agrícola (biocarvão), do qual foram obtidos para o mesocarpo bruto.

Todos os autores declararam não haver qualquer potencial conflito de interesses referente a este artigo.

\section{REFERÊNCIAS}

ASTM D 3173-87. Standard Method for Determination of Moisture Content in Biomass, Society of Testing Materials International. West Conshohocken. 2003.

ASTM D 3174-04. Standard method for ash in the analysis sample of coal and coke. West Conshohocken, 2004.

ASTM D 3175-07. Standard method for volatile matter in the analysis sample of coal. West Conshohocken, 2007.

BENTO, A.P.N.; COMINETTI, C.; SIMÕES FILHO, A.; NAVES, M. M. V. Baru almond improves lipid profile in mildly hypercholesterolemic subjects: A randomized, controlled, crossover study. Nutrition, Metabolism \& Cardiovascular Diseases, v. 24, p. 1330- 1336, 2014.

BLAMEY, J. M., FISCHER, F., MEYER, H. P., SARMIENTO, F., ZINN, M. Enzymatic biocatalysis in chemical transformations: a promising and emerging field in green chemistry practice. In: Biotechnology of Microbial Enzymes, Cap.14, p. 347-403, 2017.

BRIENZO, M.; FERREIRA, S.; VICENTIM, M. P.; SOUZA, W.; SANTANNA, C. Comparison Study on the Biomass Recalcitrance of Different Tissue Fractions of Sugarcane Culm. BioEnergy Research, v. 7,p. 1454-1465,2014.
CABRAL, M. M. S., SOUZA, A. K., ROCHA, M. S. R., ALMEIDA, R. M. R. G., GOMES, M. A. Composição da fibra da casca de coco verde in natura e após pré-tratamentos químicos. Engevista, v. 19, n. 1, p. 99-108, 2017.

FENGEL, D., WEGENER, G. Wood: Chemistry, Ultrastructure reactions. New York: W. De Gruyter, p. 613, 1984.

FERNANDES D. C., FREITAS J. B., CZEDER L. P., NAVES M. M. V. Nutritional composition and protein value of the baru (Dipteryx alata Vog.) almond from the Brazilian Savanna, Journal of the Science of Food and Agriculture, v. 90, p. 16501655, 2010.

GRASEL, F. S., STIEHL, A. C. R., BERNARDI, L. P. Inovação em Biorrefinarias I. Produção de Etanol de Segunda Geração a partir de Capim-Elefante (Pennisetum purpureum) e Bagaço de Cana-deAçúcar (Saccharum officinarum). Revista Virtual de Química, v. 9, n. 1, p. 4-14,2017.

HAYES, D. J. M.; FITZPATRICK, S.; HAYES, M. H. B.; ROSS, J. R. H. The Biofine Process Production of Levulinic Acid, Furfural, and Formic Acid from Lignocellulosic Feedstocks. Biorefineries - Industrial Process and Products, v. 1, p. 139, 2006.

HENDRIKS, A. T. W. M. e ZEEMAN, G. Pretreatments to enhance the digestibility of lignocellulosic biomass. Bioresource Technology, v. 100 , p. $10-18,2009$.

LANCEFIELD, C. S., PANOVIC, I., DEUSS, P. J., BARTA, K., WESTWOOD, N. J. Pre-treatment of lignocellulosic feedstocks using biorenewable alcohols: towards complete biomass valorisation. Green Chemistry, v. 19, n. 1, p. 202214, 2017.

LEMOS, M. R. B. A., SIQUEIRA, E. M. A., ARRUDA, S. F., ZAMBIAZI, R. C. The effect of roasting on the phenolic compounds and antioxidant potential of baru nuts [DipteryxalataVog.]. Food Research International, v. 48, p. 592-597, 2012.

NREL/TP-510-42619: Determination of Extractives in Biomass. Biomass Analysis Technology Team Laboratory Analytical Procedure, National Renewable Energy Lab, 2011a.

NREL/ NREL/TP-510-42618: Determination of structural carbohydrates and lignin in biomass. Biomass Analysis Technology Team Laboratory Analytical Procedure, National Renewable Energy Lab, 2011 b. 
OLIVEIRA, L. R., NASCIMENTO, V. M., GONÇALVES, A. R., \& ROCHA, G. J. Combined process system for the production of bioethanol from sugarcane straw. Industrial. Crops and Products,v. 8, p. 1-7, 2014.

PACHECO, T. F. Produção de etanol: primeira ou segunda geração?. Embrapa Agroenergia-Circular Técnica (INFOTECA-E), 2011.

RAMBO, M. K. D.; ALEXANDRE, G. P.; RAMBO, M. C. D.; ALVES, A. R.; GARCIA, W. T., BARUQUE, E. Characterization of biomasses from the north and northeast regions of Brazil for processes in biorefineries. Food Science and Technology, 35, n. 4, p. 605-611, 2015.

RABELO, S. C. Avaliação de desempenho do prétratamento com peróxido de hidrogênio alcalino para a hidrólise enzimática de bagaço de cana-de-açúcar. Campinas, SP. Dissertação de Mestrado. Universidade Estadual de Campinas, 2017.

ROTHENBERG, G. Catalysis: Concepts and green applications. John Wiley \& Sons. 2017

SANTOS-ROCHA, M. S. R.; SOUZA, R .B. A.; SILVA, G. M.; CRUZ, A.J.G.; ALMEIDA, E. M. R. G. Pré-tratamento hidrotérmico de resíduos do milho visando à produção de etanol de segunda geração. Scientia Plena, v. 13, n. 3, 2017.

SEIDL, P. R.; GOULART, A. K. Pretreatment processes for lignocellulosic biomass conversion to biofuels and bioproducts. Current Opinion in Green and Sustainable Chemistry, v. 2, p. 48$53,2016$.

SHELDON, R. A. The E factor 25 years on: the rise of green chemistry and sustainability. Green Chemistry, v. 19, n. 1, p. 18-43, 2016.

SHELDON, R. A.; WOODLEY, J. M. Role of biocatalysis in sustainable chemistry. Chemical Reviews, v. 118, n. 2, p. 801-838, 2017.

TAKEMOTO E.; OKADA I. Composição química da semente e do óleo de baru (Dipteryx alata Vog.) nativo do Município de Pirenópolis, Estado de Goiás. Revista Instituto Adolfo Lutz, v. 60, n. 2, p. 113-117, 2001.

VALE, A. T. e OLSEN, L. B. Produção de Carvão vegetal de casca de baru (Dipteryx alata) utilizando células de carbonização. Floresta, v. 43, n. 1, p. 117-124,2013.

WEERACHANCHAI, P. e LEE, J. M. Recyclability of an ionic liquid for biomass pretreatment. Bioresource Technology, v. 169, p. 336-343, 2014. 